\title{
Epidemiologic and Economic Impact of Natural Gas on Indoor Air Pollution in Colombia 2007
}

\author{
Nelson Alvis Guzmán ${ }^{1}$, Luis Alvis Estrada ${ }^{1}$ and \\ Fernando De la Hoz Restrepo ${ }^{2}$ \\ 1 Universidad de Cartagena \\ 2Universidad Nacional de Colombia \\ Colombia
}

\section{Introduction}

Colombian development since 1990, it can be describe according to evolution of three components of the Human Development Index: internal product, life expectancy and education. As for the gross domestic product, there has been show a slow but steady growth, excluding the 1999 crisis that resulted in a decrease of about four years, from which now is recovering. Life expectancy of Colombian population increased for about 5 years during 90th decade, because important epidemiologic and demographics changes, such as improvements in infant mortality and maternal health services, leading to a gradual recovery of the indicator, with some differences between genders, because of the greater impact than men suffered from the effect of violence. In education, there have had significant advances that although were hampered by the economic crisis, currently with the emphasis in social policies relation to education, there has been considerable improvement in the indicators. Although the overall picture is positive, there are still large differences between population groups, making equity a major challenge to human development in Colombia. Analyses by state, indicators are similar between Bogota and Hungary (country of high human development, 38th in the world) while the Chocó resemble Kenya (country of low human development, since 148 in the world). For Zones, most of the indicators in rural areas are lower than in urban areas and between social groups by deciles of the income distribution is unsatisfactory (Departamento Nacional de Planeacion de Colombia, [DNP], 1991).

In search of a universal sign for development, Colombia and 188 nations agreed at the Millennium Summit in September 2000 within the framework of the General Assembly of the United Nations, eight Millennium Development Goals in the long term, with coordination of UN, World Bank, IMF and OECD. Each country undertook to define national targets, which can be reached in 2015, for each of the Target (DNP, 1991).

However, there are studies that question the possible compliance of Colombia, some of the MDGs, especially related to poverty reduction: "... the scope in terms of poverty reduction is not so encouraging. Although according to international standards (PPP U.S. \$ 1 and \$ 2 $\mathrm{PPP})$, the country would be very close to achieving the target reduction of $50 \%$, it is clear that when the measuring stick becomes the national poverty line developments indicate that the moderate level of poverty would be only 20\% lower than the 2001 (The poverty rate 
would rise from $55.2 \%$ to $44.2 \%$ ). These results indicate that progress in other areas of society is not enough to boost the capacity of generating household income Colombians and that the strategy should focus on attacking directly additionally other determinants of poverty such as lack of access to labor markets and financial and serve the population in extreme poverty in an integrated way to break the poverty traps facing this population " (Nuñez, 2007).

In this sense, the MDGs by the different countries depends not only on the commitment of states to finance social development and undertake appropriate actions, also the contribution of civil society and the various cooperating agencies are willing to make to achieve more just societies.

Moreover, both programs targeting of social spending by the state as part of national and international, are coherent strategies for progress towards achieving better results in material development and social welfare. However, although the application of resources in development projects and / or involve social opportunities for communities to improve their capacities to address the different risks; the sole decision to implement grant programs to improve access to social services, does not mean that the results are guaranteed. Therefore, it is necessary to impact assessment procedures for specific programs and projects in order to gauge the true impact of the funds on the expected results.

\section{Household natural gas as health technology}

Living conditions, especially those related to health, an important influence on the economic situation and welfare of everyone in any society, which is particularly true in low income countries (where social safety nets are weak or nonexistent) and for the poor, due to the vicious circle of poverty and disease (Schultz, 1962). Health is considered a capital stock which the product is long lasting health, which can be used to obtain money or wages in the market for "goods" in the home or non-market sector (Grossman, 1972). It is well documented the relationship between health risk and poverty (World Health Organization [WHO], 2001).

On the other hand, the use of solid fuels for cooking and / or heating is the largest source of air pollution inside houses in the world. Nearly half of households in the world continue to use biomass fuels (wood, charcoal, dung and agricultural wastes). When biofuels are used, for example the stoves inefficient combustion, generate high concentrations of pollutants. Exposure to biomass smoke has been associated with low birth weight, acute respiratory infections, infant mortality and recently, anemia and mental retardation in children (Mishra, 2007). These pollutants, called solid fuel smoke (smoke) include respirable particulates, carbon monoxide, nitrogen oxide and sulfur, benzene, formaldehyde, 1,3 butadiene and polyaromatic compounds such as benzo (alpha) pyrene (Smith, 1987; Pandey, 1989). In households with limited ventilation, (both in developing countries and industrialized) exposure to such contaminants is higher in women and children, who stay longer in the house. Their measurements showed that concentrations of these pollutants were above the international standards (WHO) (Smith, 1987; Bruce, 2000).

The combustion of natural gas worldwide is classified as the cleanest among the traditional industrial fuels. In fact, emissions of particulate matter to meet the highest international standards, without having to invest in gas processing equipment. One of the great advantages of natural gas over other fuels, are the low combustion emissions, which can be seen in the following table (Innergy Soluciones Energeticas, 2007). 


\begin{tabular}{|l|c|c|c|}
\hline \multicolumn{1}{|c|}{ Fuel } & $\begin{array}{c}\text { MP } \\
\text { Particulado Matter }\end{array}$ & $\begin{array}{c}\text { SOX } \\
\text { Sulfur Oxide }\end{array}$ & $\begin{array}{c}\text { NOX } \\
\text { Nitric Oxide }\end{array}$ \\
\hline Gas Natural & 1 & 1 & 1 \\
\hline Gas City & 3 & 61 & 0,5 \\
\hline Gas & 1,4 & 23 & 2 \\
\hline Kerosene & 3,4 & 269 & 1,5 \\
\hline Diesel & 3,3 & 1.209 & 1,5 \\
\hline Fuel Oil N N $^{\circ}$ & 15 & 4.470 & 4 \\
\hline Fuel Oil N 6 & 39,4 & 4.433, & 4 \\
\hline Coal & 157 & 5.283 & 6 \\
\hline Firewood & 140 & 13 & 2 \\
\hline
\end{tabular}

Table 1. Concentrations of contaminants in relation to alternative fuels different of the NG

Most research on environmental pollution intradomicilliary has been conducted in developing countries and has been associated with the determination of pollutants and their sources (Spengler, 2001). This has been done by estimating the levels of risk factors generated by the combustion of biomass, through the determination of the exposure variable. To do this, Smith et al. 2004, proposes the use of the well established exposureresponse epidemiological studies conducted outside the houses and measuring concentrations of pollutants, such as an estimate of what happens inside the houses (Smith, 2004). Another approach is to use studies in developing countries, dividing the population into categories of exposed and unexposed to smoke the product of biomass burning. However, there are gaps in data on exposure of such populations, and variability between groups exposed. In addition, this method can be affected by the differential use of fuels and different mixtures of pollutants, which could prevent establishment of only two categories. Apart from the use of biomass fuels, another factor to consider is related to the ventilation conditions of housing and particularly the kitchen. This equation can build a better, in which exposure to smoke from solid fuels (biomass) is a function of the number of people using such fuels, multiplied by a factor of ventilation.

$$
P_{e} \cong P_{b} \times F_{V}
$$

$\mathrm{PE}=$ Population exposed to smoke from biofuels

$\mathrm{PB}=$ Population using biofuels

$\mathrm{FV}=$ Ventilation factor

Based on this model were estimated using solid fuels for subregions in the world (Smith, 2004). For the subregion in which America is Colombia (AMR-B), the population using solid fuels was estimated at $24.6 \%$ (CI. 18.8-30.8). This means that in Colombia about a quarter of the population could be using biofuels. Of total DALYs, it is estimated that $2.7 \%$ is attributed to diseases associated with smoke from solid fuels $(2.5 \%$ in men and $2.8 \%$ in women). Of this total, 32\% occur in Africa (AFR-D), 37\% in Southeast Asia (SEAR-D) and $16 \%$ in China, Australia and other countries (WPR-B) (Smith, 2004). Surely, that is spread by region and intra-regionally, as far as access to clean fuels is different for each region.

The strength of evidence for each factor was determined based on the structured assessment of causality, using the criteria of Bradford Hill (Hill, 1992). Therefore the specificity, doseresponse and experimental evidence is often difficult to assess environmental exposures and their health effects, we used the epidemiological evidence together with the emission 
mechanism of exposure and pollution (Smith, 2000; Zodpey, 1999). There are determined three health effects for which there is clear evidence:

1. Acute Lower Respiratory Infection

2. Chronic Obstructive Pulmonary Disease

3. Lung Cancer.

Children under 5 years are the highest exposure group, although levels are unknown globally (Ezzati, 2001; Saksena, 1992). About half of the world's countries cook with solid fuels, including more than $75 \%$ of people in India, China and nearby countries, 50 to $75 \%$ of people in some countries of South America and Africa. Inadequate ventilation in homes is a common factor in developing countries, which increases the exposure, especially for women and children who stay more time inside the house. In many measurements made by the $\mathrm{WHO}$, has been found that concentrations of pollutants inside homes exceed by a large margin, the measurements on the outside. Multiple studies have shown a consistent relationship between the use of solid fuels and several diseases. These tests show that smoke from solid fuels causes about $35.7 \%$ of the IRA, $22 \%$ of COPD and $1.5 \%$ of cancers tracheae, bronchi and lungs (WHO, 2002).

Health intervention is considered, all that technology into their practices creates possibilities of improving the living conditions of the individual and / or community. Natural gas has become a health intervention as far as a major impact not only the household economy, but can reduce the burden of respiratory diseases in the communities in which it is implemented, especially in children, women and elderly.

\section{Estimation of economic and epidemiological impact of household natural gas - analysis plan}

To perform the study combined the following studies: a) secondary data analysis (a systematic review of the literature) and analysis of databases provided by the Foundation Promigas, demographic data from DANE 2005 Census, and databases of economic statistical series of the Bank of the Republic. b) Analysis of disease burden estimated from the parameters identified in the previous studies. c) Analysis of the cost burden of illness and the estimated costs avoided then implemented the program natural gas home connections (Arredondo, 1997). d) Cost effectiveness analysis of connections of households to service natural gas home (Drummond, 2005).

The study was conducted in two phases: a) Estimating the burden of disease associated diseases biomass smoke (ARI and COPD) in the population covered by the project further at this stage to combine the results of the literature review; b) Estimating the potential economic impact of the grant program's connection to the Household Natural Gas -HNG.

The estimated population data are from field research conducted in the projected 2005 population census DANE.

We carried out an analysis of cost-effectiveness of introducing natural gas house on morbidity and mortality from respiratory diseases in children and older adults, using a simple decision that assessed the burden and costs of illness in the absence and presence of HNG.

Both share the possible scenarios in which events can be found elsewhere, for example: patients with ARF and / or IRA without COPD and / or COPD. The transition from one event to another is determined by the probability of coverage and efficiency of natural gas as a health technology. For the assessment of the model assumes that: 1) persons living in homes with natural gas which are not protected against respiratory diseases and are equally 
likely to suffer respiratory infections caused by other causes, 2) the effective protection that natural gas generates against respiratory diseases depends also on housing conditions (ventilation of the kitchen and independence and efficiency of the stove).

The study horizon is 5 years, for both children and adults, with a discount rate of $3 \%$ for both costs and outcomes. The parameters for the model shown in the following table.

\begin{tabular}{|c|c|c|c|c|}
\hline \multirow[b]{2}{*}{ Model Inputs } & \multirow[b]{2}{*}{ Base Case } & \multicolumn{2}{|c|}{ Plausible Range } & \multirow[b]{2}{*}{$\begin{array}{l}\text { Source - } \\
\text { Reference }\end{array}$} \\
\hline & & $\begin{array}{l}\text { Lower } \\
\text { Limit }\end{array}$ & $\begin{array}{l}\text { Upper } \\
\text { Limit }\end{array}$ & \\
\hline \multicolumn{5}{|c|}{ Demográphics } \\
\hline Households covered & 34.137 & & & \\
\hline Population covered & 143.861 & -- & -- & Current analysis \\
\hline Population under 5 years & 11.940 & -- & -- & Current análysis \\
\hline Population aged 60 & 14.675 & -- & -- & Current análysis \\
\hline Average monthly income per household & 174 & 137 & 250 & Current analysis \\
\hline Monthly expenditure on fuels other than HNG & 9,1 & 8,0 & 10,1 & Current analysis \\
\hline $\begin{array}{l}\text { Average monthly expenditure without grant } \\
\text { HNG }\end{array}$ & 4,0 & 3,5 & 4,5 & Current análysis \\
\hline $\begin{array}{l}\text { Average monthly expenditure on subsidized } \\
\text { HNG }\end{array}$ & 2,1 & 1,9 & 2,3 & Current análysis \\
\hline \multicolumn{4}{|c|}{ Odds (cumulative incidence) } & Current análysis \\
\hline Cumulative Incidence of IRA & 12,6 & 11,5 & 13,5 & (Constenla, 2007) \\
\hline Proportion of hospitalization & 30 & 25 & 35 & (Alvis, 2008) \\
\hline Proportion of hospital mortality & 4 & 3 & 5 & (Alvis, 2008) \\
\hline Prevalence of EPOC ${ }^{1}$ & 8,9 & 7,3 & 13,4 & (Caballero, 2005) \\
\hline f hospitalization & 30 & 25 & 35 & (Alvis, 2008) \\
\hline Proportion of hospital mortality & 8 & 5 & 11 & (Alvis, 2008) \\
\hline \multicolumn{5}{|c|}{ Effectiveness of Gas to avoid events } \\
\hline Effectiv & 62,7 & 55 & 69 & Current \\
\hline Effectiveness COPD & 26,6 & 22 & 31 & Current analysis \\
\hline \multicolumn{5}{|c|}{ Costos (US\$ 2005) } \\
\hline Average cost of patients hospitalized* & 886 & 867 & 1325 & (Constenla, 2007) \\
\hline Average cost of patients Ambulatory ARI* & 93 & 78 & 221 & (Constenla, 2007) \\
\hline Average cost of patients hospitalized COPD* & 5215 & 4800 & 5500 & (Pérez, 2007) \\
\hline Average cost of patients ambulatory COPD* & 500 & 450 & 550 & (Pérez, 2007) \\
\hline Cost of installation of HNG & 146 & 127 & 170 & Current analysis \\
\hline \multicolumn{5}{|c|}{ Weighting of disability } \\
\hline Disability weighted for ARI & 0,280 & & & (Murray, 1996) \\
\hline Disability weighted for COPD & 0,334 & & & (Murray, 1996) \\
\hline
\end{tabular}

* Includes direct and indirect costs ** Including installation costs and the average annual turnover of the home. Installation costs are deferred for 5 years

Table 2. Parameters for the economic assessment of the impact of the installation program Household Natural Gas

1 The study by (Caballero, 2005) was performed in 5539 adults of 40 years or more in 5 cities in the country (Bogotá, Bucaramanga, Medellín, Cali and Barranquilla). In conclusion the prevalence of COPD in Colombia is $8.9 \%$, with the Medellín city that was the highest percentage $13.5 \%$ and Barranquilla with the lowest $6.2 \%$. The study assessed exposure to wood smoke and found that $60.7 \%$ of the population had ever used firewood for cooking. The highest frequency, $67.5 \%$, was observed in Bucaramanga, followed by $62.5 \%$, in Cali, $59.2 \%$ in Medellín, $58.1 \%$ and $56.3 \%$ in Bogota, Barranquilla. The prevalence among men and women were similar: $60.1 \%$ in men and $61.0 \%$ in women. $64.8 \%$ have used the wood for over ten years. 
The outcome measures considered or result of the program for the model are: The total costs of the burden of respiratory disease associated with smoke from biomass, the costs of averted disease burden by the grant program to HNG connections, where both ambulatory (medical) and ARI in children hospital and COPD in older adults, deaths from these diseases and the years of disability-adjusted life (DALYs) averted.

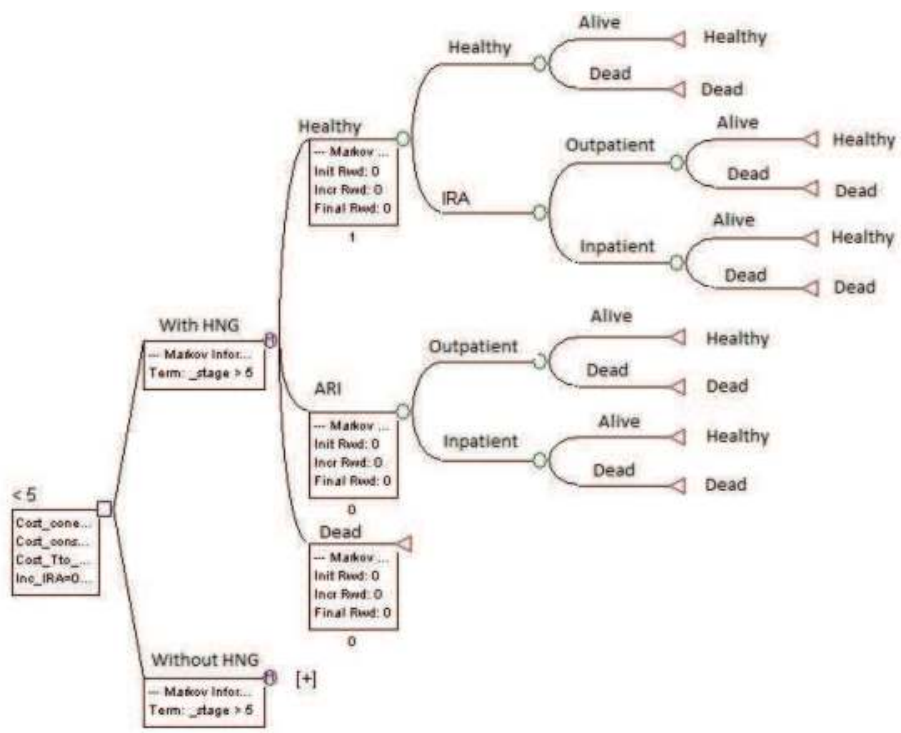

Fig. 1. Choice models for ARI.

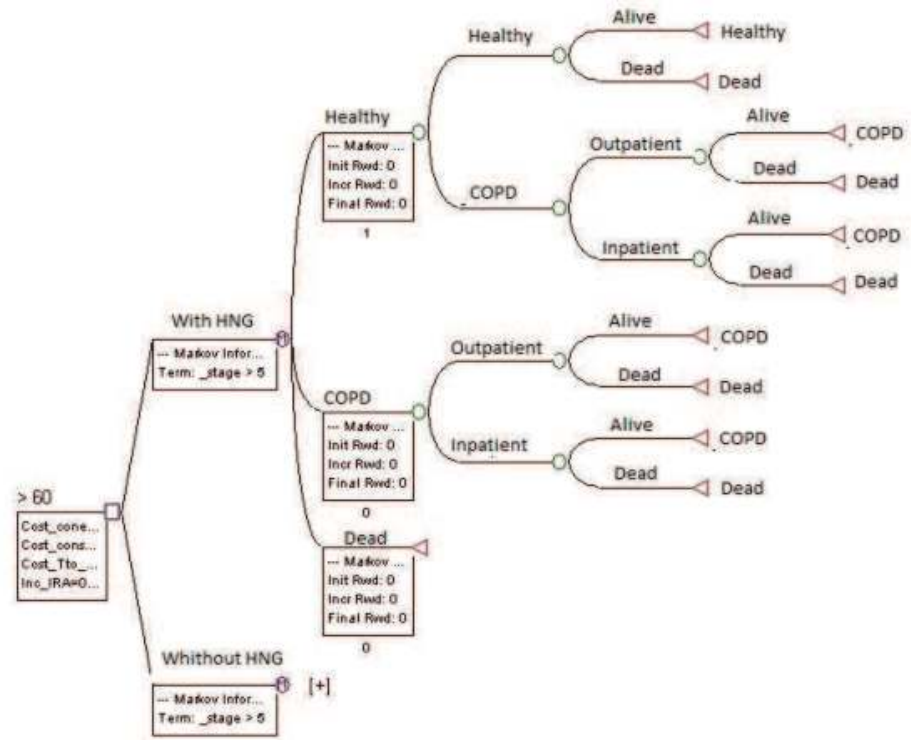

Fig. 2. Choice models for COPD 
It also uses the ratio of incremental cost-effectiveness (ICER) for comparing alternatives with and without a program using the following formula:

$$
\mathrm{ICER}=\frac{\begin{array}{l}
\text { Connections Program Costs to HNG - Avoided costs of the burden of } \\
\text { respiratory disease associated with smoke from biomass }
\end{array}}{\text { Consequently avoided (DALYs, deaths avoided, AVS) }}
$$

The ICER compares the difference in cost on the difference in health outcomes in different scenarios. For the analysis of cost effectiveness of disease avoided costs are deducted from the cost of implementing the grant program and are divided between health outcomes (life expectancy gained per woman, year of life saved, deaths prevented, etc.). The costs are expressed in dollars and pesos in 2008. All future costs and benefits are discounted at an annual rate of $3 \%$.

\subsection{Sensitivity analysis}

For the sensitivity analysis using different assumptions for the parameters. Moreover, to assess the profitability of the investment is estimated Internal Rate of Return of the project assuming that: a) all households covered by the project receive an average income between 137 and $\$ 250$ a month, b) the costs of the monthly averages without subsidy bill are $\$ 2.3$ to 1.9 , c) the average monthly cost of the subsidy bill is $\$ 4.5$ to $3.5, \mathrm{~d}$ ) all households receive a subsidy of the cost of installation HNG of $\$ 146$, and e) all households prior to the installation of the HNG, various fuels consumed by an average monthly cost between $\$ 10.1$ and 8.0.Households were followed for 20 years and yields are assumed constant.

\section{Burden of disease from ARI and COPD in population}

In 84 localities in the absence of the facilities of HNG would occur between 6288 and 7382 outpatient cases of ARI and between two thousand five hundred and five hundred thousand hospitalizations in the 5 years of observation. This could generate between 47 and 129 deaths and between 75 thousand and 127 thousand DALYs per IRA during the period. Also be presented between 5 and 9 thousand cases of outpatient visits for COPD and hospitalizations between 1200 and 3152, just as would occur between 61 and 347 deaths from COPD and between 12 thousand and 35 thousand DALYs.

As shown in Table 3, the installation of Household Natural Gas avoided during the study period, about 4 thousand to 5 thousand cases of outpatient ARI and between 1200 and 2300 for COPD. In addition, about 1,200 hospitalizations avoided by IRA and 500 COPD. Also avoid death between 45 and 170 would represent about 45 thousand to 90 thousand DALYs.

\section{Economic impact}

The economic costs of the burden of disease from ARI and COPD on stage without HNG would be between US\$10.7 and US\$23.6 million. On stage with HNG these costs would be reduced by about $32 \%$, see Table 4 .

As for the incremental cost effectiveness of the HNG would be between minus 8 thousand (cost savings) and 18 thousand dollars to avoid a death, and betwen under US\$ 16 to US\$ 17 avoid a DALY. The net cost would be from under 1.4 million dollars (cost savings) and 834 thousand dollars of 2005. 


\begin{tabular}{|c|c|c|c|c|c|c|}
\hline \multirow[b]{2}{*}{ (ARI) Events $<5$ years } & \multicolumn{3}{|c|}{$\begin{array}{c}\text { In the absence of the installation } \\
\text { of Household Natural Gas }\end{array}$} & \multicolumn{3}{|c|}{$\begin{array}{c}\text { In the presence of the } \\
\text { installation of Household } \\
\text { Natural Gas }\end{array}$} \\
\hline & Base Case & $\begin{array}{c}\text { Lower } \\
\text { Limit }\end{array}$ & $\begin{array}{l}\text { Upper } \\
\text { Limit }\end{array}$ & Base Case & $\begin{array}{l}\text { Lower } \\
\text { Limit }\end{array}$ & $\begin{array}{l}\text { Upper } \\
\text { Limit }\end{array}$ \\
\hline Outpatient cases & 6.562 & 6.288 & 7.382 & 2.165 & 2.075 & 2.436 \\
\hline Hospitalizations & 1.969 & 1.572 & 2.584 & 650 & 519 & 853 \\
\hline Deaths & 79 & 47 & 129 & 26 & 16 & 43 \\
\hline DALYs & 96.049 & 75.697 & 127.723 & 31.696 & 24.980 & 42.149 \\
\hline \multicolumn{7}{|c|}{ (COPD) Events $>60$ years } \\
\hline Outpatient cases & 6.049 & 4.906 & 9.006 & 4.476 & 3.631 & 6.664 \\
\hline Hospitalizations & 1.815 & 1.227 & 3.152 & 1.343 & 908 & 2.332 \\
\hline Deaths & 145 & 61 & 347 & 107 & 45 & 257 \\
\hline DALYs & 19.764 & 12.822 & 35.711 & 14.625 & 9.488 & 26.426 \\
\hline \multicolumn{7}{|c|}{ Total avoided events } \\
\hline \multicolumn{4}{|c|}{ Outpatient cases avoided of ARI } & 4.068 & 3.899 & 4.577 \\
\hline \multicolumn{4}{|c|}{ Hospitalizations avoided for ARI } & 1.220 & 975 & 1.602 \\
\hline \multicolumn{4}{|c|}{ Deaths avoided for ARI } & 49 & 29 & 80 \\
\hline \multicolumn{4}{|c|}{ DALYs avoided for ARI } & 59.550 & 46.932 & 79.188 \\
\hline \multicolumn{4}{|c|}{ Outpatient cases avoided of COPD } & 1.573 & 1.276 & 2.341 \\
\hline \multicolumn{4}{|c|}{ Hospitalizations avoided for COPD } & 472 & 319 & 820 \\
\hline \multicolumn{4}{|c|}{ COPD Deaths } & 38 & 16 & 90 \\
\hline \multicolumn{4}{|c|}{ COPD AVAD avoided } & 5.139 & 3.334 & 9.285 \\
\hline
\end{tabular}

Table 3. Burden of disease in the localities. Colombia 2008

\begin{tabular}{|l|c|c|c|c|c|c|}
\hline & \multicolumn{3}{|c|}{$\begin{array}{c}\text { In the absence of the } \\
\text { installation } \\
\text { of Household Natural Gas }\end{array}$} & \multicolumn{3}{c|}{$\begin{array}{c}\text { In the presence of the } \\
\text { installation of Household } \\
\text { Natural Gas }\end{array}$} \\
\hline (ARI) Events < 5 years & Base Case & $\begin{array}{c}\text { Lower } \\
\text { Limit }\end{array}$ & $\begin{array}{c}\text { Upper } \\
\text { Limit }\end{array}$ & Base Case & $\begin{array}{c}\text { Lower } \\
\text { Limit }\end{array}$ & $\begin{array}{c}\text { Upper } \\
\text { Limit }\end{array}$ \\
\hline Outpatient cases & 616.810 & 591.109 & 693.911 & 234.388 & 224.622 & 263.686 \\
\hline Hospitalizations & 1.748 .065 & 1.396 .024 & 2.294 .335 & 664.265 & 530.489 & 871.847 \\
\hline Subtotal costs ARI & 2.364 .874 & 1.987 .133 & 2.988 .246 & 898.652 & 755.111 & 1.135 .533 \\
\hline (COPD) Events > 60 years & & & & & & \\
\hline Outpatient cases & 3.024 .324 & 2.453 .063 & 4.502 .883 & 2.238 .000 & 1.815 .267 & 3.332 .133 \\
\hline Hospitalizations & 9.279 .836 & 6.272 .482 & 16.119 .419 & 6.867 .079 & 4.641 .637 & 11.928 .370 \\
\hline Subtotal costs COPD & 12.304 .160 & 8.725 .545 & 20.622 .302 & 9.105 .079 & 6.456 .903 & 15.260 .503 \\
\hline Total Cost Burden & 14.669 .035 & 10.712 .678 & 23.610 .547 & 10.003 .731 & 7.212 .014 & 16.396 .037 \\
\hline \multicolumn{2}{|c|}{ Total costos avoided by the project } & 4.665 .304 & 3.500 .664 & 7.214 .511 \\
\hline \multicolumn{2}{|c|}{ Total installation costs of GND } & 4.984 .002 & 4.335 .399 & 5.803 .290 \\
\hline Cost/Deaths avoided for the period & 3.682 & -8.289 & 18.473 \\
\hline Cost / DALY avoided for the period & 5 & 17 & -16 \\
\hline \multicolumn{2}{|c|}{ Total neto costs for the period } & 318.698 & -1.411 .221 & 834.735 \\
\hline
\end{tabular}

Table 4. Costs of Burden of disease in the localities. Colombia 2008 
Other benefits generated by the HNG connection to households are the savings that are generated by stop using different fuel HNG which is more than twice as costly as paying the monthly bill in the event that households do not receive service subsidies from the State. In the scenario where households receive the state subsidy of these costs can be up to 4 times what the household pays each month for the service. If we assume that these households maintained this condition for about 20 years, it is possible to evaluate returns on those savings can generate the initial investment by the donor (grant connect HNG).

\begin{tabular}{|l|c|c|c|}
\hline Ítems & Average & Lower Limit & Upper Limit \\
\hline Total household income & $1.096 .087 .341,3$ & $865.834 .808,4$ & $1.569 .325 .590,3$ \\
\hline Spending on different fuel to GND & $57.009 .359,7$ & $50.367 .234,2$ & $63.652 .387,1$ \\
\hline GND spending without subsidy & $25.109 .209,4$ & $21.970 .558,3$ & $28.247 .860,6$ \\
\hline GND spending with subsidy & $13.182 .335,0$ & $11.926 .874,5$ & $14.437 .795,4$ \\
\hline State subsidies & $11.926 .874,5$ & $10.043 .683,8$ & $13.810 .065,2$ \\
\hline Savings without subsidies & $31.900 .150,3$ & $28.396 .676,0$ & $35.404 .526,5$ \\
\hline Savings with subsidies & $43.827 .024,8$ & $38.440 .359,8$ & $49.214 .591,7$ \\
\hline $\begin{array}{l}\text { Internal Rate of Return without } \\
\text { subsidies }\end{array}$ & $42 \%$ & $37 \%$ & $46 \%$ \\
\hline $\begin{array}{l}\text { Internal Rate of Return without } \\
\text { subsidies }\end{array}$ & $57 \%$ & $50 \%$ & $64 \%$ \\
\hline
\end{tabular}

Table 5. Financial return of the project for households for 20 years. Colombia 2008

Adding these savings to the costs avoided by the impact of the HNG on the incidence of respiratory diseases, we can assess the IRR of the project from the perspective of the donor, assuming that their interest is the achievement of maximum benefit to each household subsidized. As shown in Figure 3 the IRR is positive in both scenarios (with and without subsidies) as low as $44 \%$ during the first five years and a maximum of $78 \%$ if the period of observation is 20 years, this scenario without the subsidy cost of the bill (consumer subsidy). These numbers vary in the same scenario with allowance for consumption of between $65 \%$ and $96 \%$ when we evaluated the project to 20 years.

\section{Sensitivity analysis of the results}

As shown in Figure 4, a sensitivity analysis in a way to display the variables that have the greatest impact incremental effect on the cost of connecting homes to the HNG are: a) the prevalence of COPD, b) the costs of HNG installation, c) the effectiveness of the HNG to impact the prevalence of COPD, d) the proportion of hospitalizations for COPD and e) the average costs of outpatient and hospitalization ARI. In this regard, the decision to subsidize the costs of installing the HNG in poor households, allowing for an intervening variable of greatest impact for the evaluation of benefits of installing. 


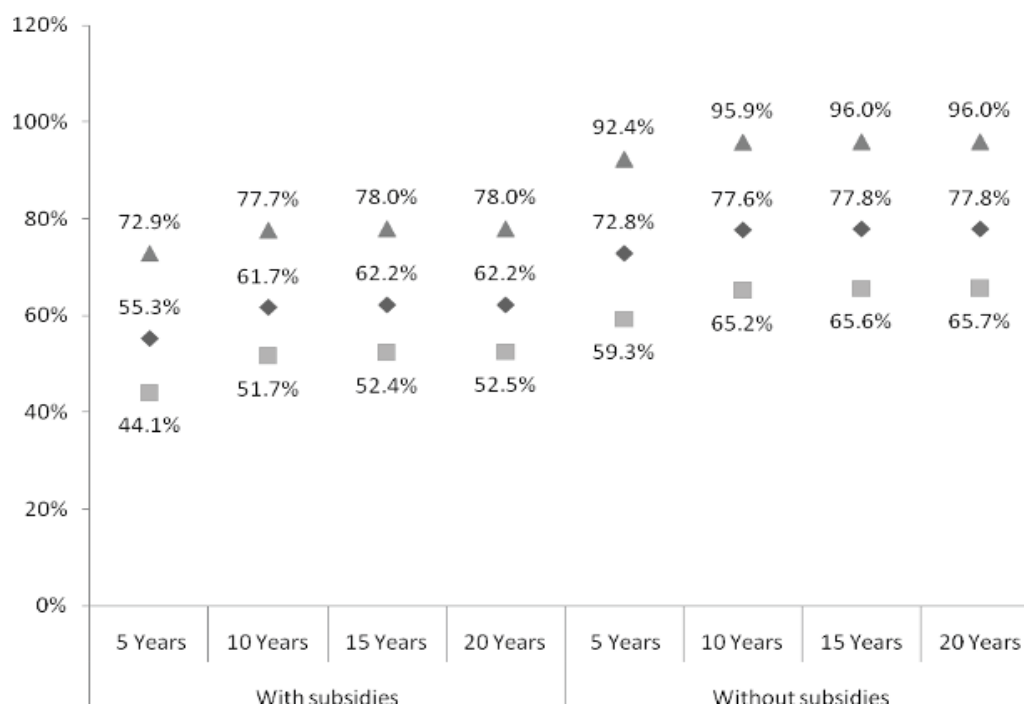

Fig. 3. Internal rate of return of the the installation of Household Natural Gas.

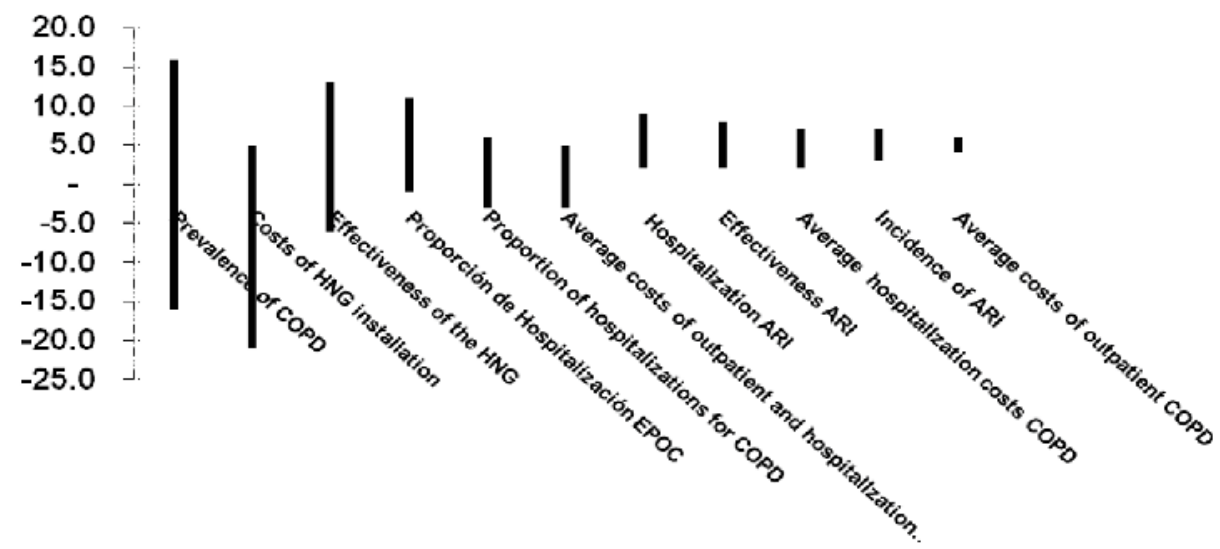

Fig. 4. Tornado Diagram of ICER of Cost/DALYs

\section{Conclusion}

According to the DANE census of 2005 in Colombia were 9.74 million households of which 3.92 million $(40.3 \%)$ accessed the service of HNG. For the fourth quarter of 2008 the Ministry of Mines and Energy of Colombia reported 4.93 million homes connected to the HNG (Murray, 1996), which represents a growth of more than one million homes in three years and covers over $50 \%$ of all households. These households are concentrated in 462 locations 
in about 350 municipalities in 22 of the 33 departments in the country. Of these households, $55 \%$ belong to strata 1 and 2 (Murray, 1996). Since according to the quality of life survey 2003 (Alzate, 2006) 95.5\% of rural households in Colombia belong to the socioeconomic strata 1 and 2, we can say that the coverage in the poorest and most vulnerable populations are not yet adequate.

On the other hand, this demonstrated the increased risk of ARI, COPD and lung cancer in those households who cook with biofuels (Norman, 2007). In our study, the limited information, only measure the disease burden of ARI and COPD which assumes an underestimation of the protective effects of GND, for example, about lung cancer. However, as shown, assuming the WHO criteria (WHO, 2001), the GND is a highly cost effective technology and thus its incorporation into benefits for the social development of poor and marginalized communities, is beyond dispute.

Thus, this study is a good estimator of the potential impact of universal access to GND by the poorest and most vulnerable households, which are precisely those that generate the greatest burden of disease by the pollution. This investigation provides means of support of public policy with a view to providing decision makers to mitigate or eliminate pollution as change or improve the efficiency of the stoves, fuel switching to biomass use GND generating reducing the frequency of cases of ARI, COPD and other respiratory diseases and the reorientation and improvement in the household economy (Larson, 2002).

These findings are consistent in scale, with the referenced document CONPES 3344 through 2005 which set out "guidelines for the formulation of policy on prevention and control of air pollution" (DNP, 2005) and estimated that in Colombia, According to Larsen, is generated per year 6000 deaths, 7400 new cases of chronic bronchitis (COPD), 13000 hospitalizations and 255000 visits to emergency rooms, with costs between 230 and 600 billion pesos in 2004 ie between about 100 and 270 million dollars.

In Colombia there are already incentives rule (Article 97 of Act 142 of 1994) which facilitate the implementation of the policy of subsidies: "In any case, the cost of household connection, attack and meter of stratas 1,2 and 3 can be covered by the municipality, the department or the nation through budgetary support, but political will is an important input to achieve the goals for the reduction of pollution by smoke from biomass. However, given the high rates of return for this project ( $37 \%$ and $46 \%$ in cases that do not subsidize the consumption of the service and between $50 \%$ and $64 \%$ in the scenario with subsidies from the state) is very difficult to escape of these choices.

In summary we can state that: 1) Given the high rates of return of the project, both on stage and without subsidies subsidized consumption, for every $\$ 100$ invested by the donor in the year zero of the project, households received net benefits of between 65 and 96 dollars annually. 2) Decisions to invest in subsidizing the connection of poor households to the GND are highly cost effective, to be cost saving, especially in poorer households with higher risks of respiratory diseases (health risk) and lower income (economic risk) is say the most vulnerable. So, with less than $\$ 20$ is spent a year of life saved, which in the worst case is 8 times lower than required to save a year of life using the pneumococcal vaccine, which needs between \$ 154 and \$ 5252 in different countries of Latin America and the Caribbean (Constenla, 2007; Sinha, 2008). 3) If the state took the decision to subsidize both the connection and GND consumption by households more vulnerable, more could be close to achieving the MDGs, as is clearly demonstrated improvements in quality of life households and high social return on investment in this area, which is essential in the fight against poverty and misery in our country. 


\section{References}

DNP. Departamento Nacional de Planeación.. (2005). Metas y estrategias de colombia para el logro de los objetivos de desarrollo del milenio - 2015, In : Consejo Nacional de Política Económica y Social República de Colombia, Conpes 091. Bogotá D.C.

Nuñez, J; Gonzalez, N. \& Hernández, G. (2007). ¿Es posible alcanzar los objetivos del Milenio en Colombia? Una evaluación de estrategias de focalización y financiamiento, In: Archivos de Economía No 330. Departamento Nacional de Planeación, Dirección de Estudios Económicos: Bogotá D.C., Colombia.

Schultz, T. (1962). Reflections on investment in man. Journal of Political Economy, Vol. 70, pp. 101-109.

Grossman, M. (1972). On the concept of health capital and the demand for health. Journal of Political Economy, Vol. 80, No. 2, (March-April 1972), pp. 223-255.

WHO, World Health Organization (2001). Macroeconomics and health: investing in health for economic development. Report of the Commission on Macroeconomics and Health. In : Commission on Macroeconomics and Health, Geneva.

Mishra, V. \& Retherford R. (2007). Does biofuel smoke contribute to anaemia and stunting in early childhood? Int J Epidemiol, Vol. 36, No. 1, pp. 117-29.

Smith, K. (1987). Biofuels, air pollution and Health: a global review. Plenum, Editor. ISBN: 0306-42519-X, New York.

Pandey, M; Smith, K; Boleij, J. \& Wafula, E. (1989). Indoor air pollution in developing countries and acute respiratory infection in children. Lancet, Vol. 333, No. 8635, pp. 427-9.

Bruce, N; Perez, R. \& Rachel, A. (2000). Indoor air pollution in developing countries: a major environmental and public health challenge. In: Bulletin of the World Health Organization, Vol. 78, No. 9, pp. 1067-1071.

Agency, U.S.E.P. (1997). Revisions to the National Ambient Air Quality Standards for Particles Matter. Federal Register. pp. 38651-38701.

Innergy Soluciones Energeticas. (2007). Ventajas Para el Medio Ambiente. Ventajas del Gas Natural, 02.10.2007, Available from: http://www.innergy.cl/ventajas1.htm.

Spengler, J ; Samet, J. \& McCarthy, J. (2001). Indoor Air Quality handbook., ISBN: 0-07445549-4. New York: McGraw Hill.

Smith, K ; Mehta, S. \& Maeusezahl, F. (2004). Indoor Air Pollution from Household Use of Solid Fuels. In : Comparative quantification of health risks: Global and regional burden of disease due to selected major risk factors, World Health Organization: Geneva.

Hill, A. \& Hill, I. (1992). Bradford Hill's Principles of Medical Statistics. Biometrics. Vol. 48, No. 2, pp. 659-660.

Smith, K. ; Samet, J ; Romieu, I. \& Bruce, N. (2000). Indoor air pollution in developing countries and acute lower respiratory infections in children. Thorax. Vol. 55, No. 6, pp. 518- 532.

Zodpey, P. \& Ughade, S. (1999) Exposure to cheaper cooking fuels and risk of agerelated cataract in women. Indian Journal of Occupational and Environmental Medicine, Vol. 3, No 4,(Oct- Dec 1999) pp. 159-161. 
Ezzati, M. \& Kammen, D. (2001). Quantifying the effects of exposure to indoor air pollution from biomass combustion on acute respiratory infections in developing countries. Environmental Health Perspectives, Vol. 109, No. 5, (May 2001) pp. 481-488.

Saksena, S .; Prasad, R.; Pal, R. \& Joshi, V. (1992). Patterns of daily exposure to TSP and CO in the Garhwal, Himalaya. Atmospheric Environment, Vol. 26A, No. 11, (August 1992), pp. 2125-2134.

WHO, World Health Organization. (2002). Addressing the links between indoor air pollution, household energy, and human health. In : Meeting report of the WHOUSAID global consultation on the health impact of indoor air pollution and household energy in developing countries, Geneva.

Caballero, A; Torres, C. ; Maldonado, D. ; Jaramillo, C. \& Guevara, D. (2005). Prevalencia de la Enfermedad Pulmonar Oclusiva Crónica en cinco ciudades colombianas. Revista Médica Sanitas. Edición Especial.,.

Alvis, N; Alvis, L. \& Orozco, J. (2008). The cost-effectiveness of installing natural gas as a sanitary alternative for rural communities on the Colombian Caribbean coast burning biomass fuels. Rev. salud pública, Vol. 10, No. 4, (september 2008) pp. $537-549$.

Pérez, N ; Murillo, R. ; Pinzón, C. \& Hernández, G. (2007). Smoking Attributable Costs of Lung Cancer, COPD, and AMI in Colombia (A PAHO Multicentric Proyect). Rev Colomb Cancerol. Vol. 11 No. 4, (December 2007) pp. 241 - 249.

Arredondo, A. \& Damian, T. (1997). The economic costs in the production of health services: from the cost of inputs to the cost of case management. Salud Publica Mex, Vol. 39, No. 2, pp. 117-24.

Drummond, M. ; O'brien, B. ; Stoddart, G. \& Torrance, G. (2005). Methods for the economic evaluation of health care programs. ISBN 0198529457. Third Edition ed., Oxford Medical Publications Oxford GB:

Murray, C. \& Lopez, A. (1996). The Global Burden of Disease. Boston: Harvard University Press, .

Alzate, M. (2006). La estratificación socioeconómica para el cobro de los servicios públicos domiciliarios en Colombia ¿Solidaridad o focalización?. In : Estudios y Perspectivas 14, ISBN: 92-1-322968-2, Bogotá D.C..

Norman, R. ; Barnes, B. ; Mathee, A. ; Bradshaw, D. \& South African Comparative Risk Assessment Collaborating Group. (2007). Estimating the burden of disease attributable to indoor air pollution from household use of solid fuels in South Africa in 2000. S Afr Med J, (August 2007), Vol. 97, No. 8 Pt 2, pp. 764-71.

Larson, B. \& Rosen, S. (2002). Understanding household demand for indoor air pollution control in developing countries. Soc Sci Med, Vol. 55, No. 4, pp. 571-84.

DNP, Departamento Nacional de Planeación,. (2005). Lineamientos para la formulación de la política de prevención y control de la contaminación del aire. In : Consejo Nacional de Política Económica y Social República de Colombia, Conpes 3344. Bogotá D.C.

Constenla D. ; Gomez E.; De la Hoz, F.; O'Loughlin, R.; Sinha, A.; Valencia, J. \& Valenzuela, M. (2007) The Burden of Pneumococcal Disease and the Cost Effectiveness of a Pneumococcal Vaccine in Latin America and the Caribbean: A review of the evidence and a preliminary economic analysis. Available from: http://www.sabin.org. 
Sinha, A. ; Constenla D. \& O'Loughlin, R.; Gomez E.; De la Hoz, F. ; Valencia, J. ; Valenzuela, M. \& De Qadros, C. (2008). Cost-effectiveness of pneumococcal conjugate vaccination in Latin America and the Caribbean: a regional analysis. Rev Panam Salud Publica, (November 2008)Vol. 24, No. 5, pp. 304-13. 


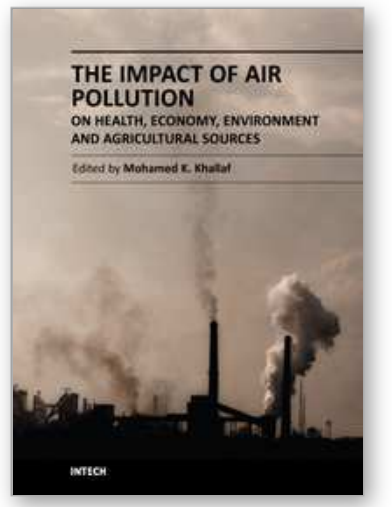

\author{
The Impact of Air Pollution on Health, Economy, Environment and \\ Agricultural Sources \\ Edited by Dr. Mohamed Khallaf
}

ISBN 978-953-307-528-0

Hard cover, 444 pages

Publisher InTech

Published online 26, September, 2011

Published in print edition September, 2011

This book aims to strengthen the knowledge base dealing with Air Pollution. The book consists of 21 chapters dealing with Air Pollution and its effects in the fields of Health, Environment, Economy and Agricultural Sources. It is divided into four sections. The first one deals with effect of air pollution on health and human body organs. The second section includes the Impact of air pollution on plants and agricultural sources and methods of resistance. The third section includes environmental changes, geographic and climatic conditions due to air pollution. The fourth section includes case studies concerning of the impact of air pollution in the economy and development goals, such as, indoor air pollution in México, indoor air pollution and millennium development goals in Bangladesh, epidemiologic and economic impact of natural gas on indoor air pollution in Colombia and economic growth and air pollution in Iran during development programs. In this book the authors explain the definition of air pollution, the most important pollutants and their different sources and effects on humans and various fields of life. The authors offer different solutions to the problems resulting from air pollution.

\title{
How to reference
}

In order to correctly reference this scholarly work, feel free to copy and paste the following:

Nelson Alvis Guzmán, Luis Alvis Estrada and Fernando De la Hoz Restrepo (2011). Epidemiologic and Economic Impact of Natural Gas on Indoor Air Pollution in Colombia 2007, The Impact of Air Pollution on Health, Economy, Environment and Agricultural Sources, Dr. Mohamed Khallaf (Ed.), ISBN: 978-953-307-5280, InTech, Available from: http://www.intechopen.com/books/the-impact-of-air-pollution-on-health-economyenvironment-and-agricultural-sources/epidemiologic-and-economic-impact-of-natural-gas-on-indoor-airpollution-in-colombia-2007

\section{INTECH}

open science | open minds

\author{
InTech Europe \\ University Campus STeP Ri \\ Slavka Krautzeka 83/A \\ 51000 Rijeka, Croatia \\ Phone: +385 (51) 770447 \\ Fax: +385 (51) 686166 \\ www.intechopen.com
}

\author{
InTech China \\ Unit 405, Office Block, Hotel Equatorial Shanghai \\ No.65, Yan An Road (West), Shanghai, 200040, China \\ 中国上海市延安西路65号上海国际贵都大饭店办公楼 405 单元 \\ Phone: +86-21-62489820 \\ Fax: +86-21-62489821
}


(C) 2011 The Author(s). Licensee IntechOpen. This chapter is distributed under the terms of the Creative Commons Attribution-NonCommercialShareAlike-3.0 License, which permits use, distribution and reproduction for non-commercial purposes, provided the original is properly cited and derivative works building on this content are distributed under the same license. 